\title{
Genomic and Phylogenetic Analysis of Hepatitis C Virus Isolates from Argentine Patients: a Six-Year Retrospective Study
}

\author{
J. F. QUARLERI, ${ }^{1}$ B. H. ROBERTSON,${ }^{2}$ V. L. MATHET, ${ }^{1}$ M. FELD,${ }^{1}$ L. ESPÍNOLA,${ }^{1}$ M. P. REQUEIJO,${ }^{3}$ \\ O. MANDÓ, ${ }^{3}$ G. CARBALLAL, ${ }^{3}$ AND J. R. OUBIÑA ${ }^{1 *}$ \\ Laboratorio de Hepatitis Virales, Departamento Microbiología, Facultad de Medicina, Universidad de Buenos Aires, ${ }^{1}$ \\ and CEMIC, ${ }^{3}$ Buenos Aires, Argentina, and Centers for Disease Control and Prevention, Atlanta, Georgia ${ }^{2}$
}

Received 15 November 1999/Returned for modification 30 June 2000/Accepted 7 September 2000

\begin{abstract}
Typing of hepatitis $\mathrm{C}$ virus (HCV) isolates from Argentine patients was performed by using different methodologies in a population of 243 patients. HCV subtype was assigned based upon restriction fragment length polymorphism (RFLP). HCV RNA genomes obtained from serum samples were classified as belonging to clade 1 (53.5\%), 2 (23.0\%), or $3(8.6 \%) ; 14.8 \%$ of samples showed HCV mixed infections, more frequently implying different subtypes within the same clade. In addition to RFLP typing, phylogenetic relatedness among sequences from both $5^{\prime}$ untranslated region $(n=50)$ and nonstructural $5 B$ coding region $(n=15)$ was established.
\end{abstract}

Hepatitis $\mathrm{C}$ virus ( $\mathrm{HCV})$, the causative agent of most cases of non-A, non-B hepatitis, exists as a heterogeneous group of viruses sharing at least $65 \%$ homology among different strains. This virus has a positive-sense, single-stranded RNA genome of approximately $9.5 \mathrm{~kb}$. There are three functional regions of the genome, the $5^{\prime}$ untranslated region (5'UTR), the coding region encoding the structural and nonstructural viral proteins, and the 3'UTR. When different strains of HCV are compared, nucleotide sequence variation is unevenly distributed throughout the genome, ranging from segments within the coding regions with high variability (such as for envelope proteins) to the highly conserved 5'UTR region. Sequence analysis performed on isolates from different geographic areas around the world has revealed the presence of six genetic clusters which have been recently classified as clades 1 to 6 (42).

Several methodologies have been developed for identification of genetic groups of HCV. Among them, two noncommercial ones are widely used when a large number of samples are being studied: restriction fragment length polymorphism (RFLP) analysis of PCR amplicons from the 5'UTR (9) and core-based PCR typing $(28,30,31)$. However, the subtype assignment is strongly recommended to be based upon sequence analysis on $\mathrm{HCV}$ coding regions such as core, E1 or NS5B (42).

Since data regarding $\mathrm{HCV}$ genomic characteristics from South America are still scarce, the aim of the present study was to characterize the clade and subtype distribution of different isolates from chronically $\mathrm{HCV}$-infected Argentine patients. To reach this goal, three different methodologies were used, including cDNA sequencing and phylogenetic analysis of selected samples, supported by bootstrap resampling.

\section{MATERIALS AND METHODS}

Patients. From 1993 to 1999 we characterized 243 HCV isolates from three different groups of viremic patients (nonhemophiliac and naive of antiviral therapy). The first group comprised 129 patients with parenteral risk of viral infection, including 56 blood transfusion patients, 40 intravenous drug users (IVDU), 15 hemodialysis patients, and an additional 18 individuals who had a history of potential parenteral routes for viral exposure (undergoing surgery, having a tattoo or acupuncture, being a laboratory professional, or practicing homosexual

* Corresponding author. Mailing address: Dto. Microbiología, Fac. de Medicina, UBA, Paraguay 2155, Piso 11, (1121) Buenos Aires, Argentina. Phone: 54-11-4508-3689. Fax: 54-11-4508-3705. E-mail: joubina@fmed.uba.ar. behavior). The second group $(n=8)$ included patients with nonparenteral risk (either having nonmarital household contact with an infected individual or being a drug addict who uses oral or nasal routes of drug entry). The third group ( $n=$ 106) was composed of sporadic or community-acquired cases. The mean age \pm standard deviation (SD) in the whole study group was $43.3 \pm 24.8$ years (range, 2 to 73 years), with a gender distribution showing male predominance $(60.5 \%)$. Age ranges were not equally represented among different groups of patients. The mean $\pm \mathrm{SD}$, median, and range (1st to 3 rd quartile) for each group were, respectively, as follows: for transfused patients, $24.6 \pm 21.2,16$, and 8 to 36 ; for IVDU, $33.3 \pm 10.2,30$, and 26.5 to 35.5 ; for dialyzed patients, $28.4 \pm 14.4,31$, and 21 to 35 ; for sporadic cases, $50.0 \pm 17.4,55.0$, and 39.5 to 64 ; for health workers, $47.9 \pm 9.5,45$, and 41 to 56 ; for other parentally infected patients, $41.6 \pm 20.0,44.5$, and 30.7 to 58.7 ; and, lastly, for other nonparentally infected patients, $43.0 \pm 10.1,39$, and 38.2 to 43.7 .

Informed consent to participate in the study was provided by all patients or their parents. Two hundred twenty-five patients were adults, and 18 were pediatric patients. All serum samples were analyzed by 5'UTR RFLP. In addition, selected cases were studied using other methodologies, as shown in Table 1.

Serum alanine aminotransferase (ALT) levels were determined by using a commercial kit (BioSystems) according to the manufacturer's instruction. Normal ALT levels were $\leq 35 \mathrm{U} /$ liter when testing was done at $37^{\circ} \mathrm{C}$.

RNA extraction, RT-nested PCR of the 5'UTR, and RFLP analysis. RNA was extracted from $200 \mu \mathrm{l}$ of serum using guanidinium isothiocyanate and acidic phenol followed by reverse transcription (RT)-nested PCR amplification of the 5'UTR as previously described (33). The HCV 5'UTR amplicons obtained (210 bp) were characterized by RFLP (9) as modified by the authors $(33,39,41)$. This procedure was applied to the whole population analyzed (Table 1).

PCR amplification of other genome regions. Core-based genotyping was performed as previously described (33) and was initially used to analyze HCV strains from 56 consecutive patients included within this study (core PCR [Table 1]). This methodology was subsequently discontinued, since a significant percentage of the isolates could not be typed. For selected samples an improved version of this method was employed in order to detect the HCV 2c subtype (26).

RT-nested PCR amplification of an NS5B fragment (nucleotides 7975 to 8196) as previously described $(6,11)$ was performed on 34 samples selected because they (i) had discrepant results between core-based genotyping and 5'UTR RFLP $(n=6)$, (ii) were nontypeable by the core-based methodology $(n=26)$, or (iii) had unrecognized RFLP patterns within the 5'UTR, resulting in inconclusive subtype assignment $(n=2)$. Since only 56 specimens had been previously tested by the core-based RT-nested PCR, we cannot rule out the possibility that more specimens would have yielded discrepant results between such a method and 5'UTR RFLP.

5'UTR-core RFLP. In order to confirm mixed infections involving subtypes 1a and $1 \mathrm{~b}$ detected by 5'UTR RFLP, amplicons of 647 bp partially encompassing both the 5'UTR and the core were obtained by RT-heminested PCR using primers HCV2 (outer sense), HCV4 (inner sense), and 186 (antisense) as described previously $(33,41)$, using the same cycling conditions reported for corebased PCR (33). Bands of the expected size were purified and digested for $6 \mathrm{~h}$ with $A c c$ I. As reported elsewhere $(2,3)$, this endonuclease recognizes two restriction sites within 1a amplicons (fragments of 225, 192, and $230 \mathrm{bp}$ ) and one restriction site within $1 \mathrm{~b}$ (or 1c) amplicons (fragments of 225 and $417 \mathrm{bp}$ ) (Fig. 1).

Avoidance of PCR contamination. PCR amplification of all three genome regions (5' UTR, core, and NS5B) strictly followed the recommendations of Kwok and Higuchi (21). In addition, different sets of micropipettes and special 
TABLE 1. HCV genomic characterization studies performed with 243 samples

\begin{tabular}{|c|c|c|c|c|}
\hline \multirow[b]{2}{*}{ Group } & \multicolumn{4}{|c|}{ No. of samples positive by: } \\
\hline & $\begin{array}{c}\text { 5'UTR RFLP } \\
\text { analysis }\end{array}$ & $\begin{array}{l}\text { Core } \\
\text { PCR }\end{array}$ & $\begin{array}{l}5^{\prime} \text { UTR cDNA sequencing, } \\
\text { phylogenetic analysis, } \\
\text { and predicted RFLP }\end{array}$ & $\begin{array}{l}\text { NS5B cDNA sequencing } \\
\text { and phylogenetic } \\
\text { analysis }^{a}\end{array}$ \\
\hline 5'UTR RFLP only $(n=148)$ & 148 & & & \\
\hline Concordant $5^{\prime}$ UTR RFLP analysis and $5^{\prime}$ UTR cDNA sequencing ${ }^{b}(n=37)$ & 37 & & 37 & \\
\hline $\begin{array}{l}\text { Concordant } 5 \text { 'UTR RFLP analysis and } 5^{\prime} \text { UTR cDNA sequencing but } \\
\text { discrepant versus core PCR }(n=1)\end{array}$ & $1^{c}$ & 1 & 1 & 1 \\
\hline Discrepant 5 'UTR RFLP analysis versus core PCR $(n=6)$ & 6 & 6 & & \\
\hline $\begin{array}{l}\text { Concordant } 5 \text { 'UTR RFLP analysis and } 5^{\prime} \text { UTR cDNA sequencing but } \\
\text { nontypeable by core PCR }(n=12)\end{array}$ & 12 & 12 & 12 & 12 \\
\hline Typed by $5^{\prime}$ UTR RFLP analysis but nontypeable by core PCR $(n=14)$ & 14 & 14 & & \\
\hline Concordant $5^{\prime}$ UTR RFLP analysis and core PCR $(n=23)$ & 23 & 23 & & \\
\hline Unrecognized subtype by $5^{\prime}$ UTR RFLP analysis $(n=2)$ & 2 & & & 2 \\
\hline Total & 243 & 56 & 50 & 15 \\
\hline
\end{tabular}

${ }^{a}$ Only 15 out of 34 studied sera were NS5B PCR positive.

${ }^{b}$ Four samples exhibited mixed infections by RFLP, showing the predominant population also documented by cDNA sequencing, in addition to minor HCV population(s).

${ }^{c}$ Minor population of type 1 (plus $2 \mathrm{a} / \mathrm{c}$ ) was also detected in 3 out of 10 RT-nested 5'UTR PCR amplifications followed by RFLP analysis of isolate 760.

aerosol-resistant tips (Molecular Bio-Products, Inc.) were used for each procedure from serum collection to agarose gel analysis of the PCR products. To validate results, a negative control was included from the extraction step for every four samples, and another negative control was also added from RT. A positive control was included from RNA extraction. Separate rooms were used for PCR preamplification, amplification, and gel loading. Mixed infections were confirmed by duplicate analysis from two different serum aliquots.

Sequencing of 5'UTR and NS5B amplicons. The 5'UTR $(n=50)$ and NS5B $(n=15)$ PCR products were purified as previously described (40), and the fragments were sequenced (43) using both sense and antisense primers with $5^{\prime}$ -end-fluorescent-labeled dideoxynucleotides in an automatic sequencer (ABI 373A; Applied Biosystems, Foster City, Calif.). To avoid misinterpretations, each template was obtained from at least two different aliquots of RNA and sequenced bidirectionally.

Selected samples for 5'UTR cDNA sequencing were (i) 13 out of the 33 samples which had exhibited either nontypeable $(n=26)$ or discrepant results compared with 5'UTR RFLP $(n=7)$, according to the core-based typing method; and (ii) 37 others representative of the different groups studied, including parenteral risk of infection $(n=25)$, nonparenteral risk $(n=7)$, and sporadic cases $(n=5)$. The above-mentioned set of 13 samples was randomly selected in order to test the accuracy of data already obtained by $5^{\prime}$ UTR RFLP (Table 1 ).

Phylogenetic methods. The clade and subtype for each sample was determined by sequence comparison with prototypic strains followed by further phylogenetic analysis. The DNA alignments were generated with the Clustal X program (48). Evolutionary distances between sequences were determined with the DNADIST program (Kimura two-parameter method) of the PHYLIP package, version 3.5c (13). The phylogenetic tree was constructed with the TREEVIEW program, as previously described (40). Bootstrap analysis was performed by using the programs SEQBOOT (to generate 1,000 reshuffled sequences), CONSENSE, and RETREE at the midpoint of the longest branch for comparative purposes.

HCV serologic genotyping. Selected samples $(n=3)$ showing mixed infections ascribed to different genotypes were studied by enzyme-linked immunosorbent assay by means of a commercial test to detect antibodies against type-specific HCV NS4 peptides (MUREX HCV, Serotyping 1-6 Assay; Murex, Buenos Aires, Argentina).

Statistical analysis. Statistical differences were calculated by means of parametric tests (comparison of two sample proportions or Student's $t$ test) or nonparametric tests (by the chi-square test with Yates' correction, and by Fisher's exact test when $8 \leq N \leq 75$, where $N$ is the sum of the values in a given table). Tadpole III program (Biosoft, Cambridge, United Kingdom) was used throughout this study. The median age and the 1st and 3rd quartile range from each population group were calculated by using the Excel program from the Office 97 Microsoft package.

Nucleotide sequence accession numbers. Nucleotide sequence data reported in this paper were deposited in the GenBank database with the following accession numbers: AF041264 to AF041313 (5'UTR sequences) and AF041314 to AF041328 (NS5B sequences).

\section{RESULTS}

RFLP analysis of 5'UTR amplicons. Out of 243 samples, clade 1 was detected in $130(53.5 \%)$, clade 2 was detected in 56 $(23.0 \%)$, and clade 3 was detected in $21(8.6 \%)$ samples. Thir- ty-six samples (14.8\%) showed mixed infections, involving different clade and subtype combinations (Table 2). Infections ascribed by RFLP to a unique subtype within clades 1 or 2 were classified as follows: within clade 1 , subtype $1 \mathrm{a} / \mathrm{c}$ was found in 57 samples $(23.4 \%)$, while subtype $1 \mathrm{~b}$ accounted for the remaining $73(30.0 \%)$; clade 2 included 47 samples regarded as subtype $2 \mathrm{a} / \mathrm{c}(19.3 \%)$ and 9 samples regarded as subtype $2 \mathrm{~b} / \mathrm{c}$ (3.7\%); within clade 3 , all samples $(n=21)$ were characterized as subtype $3 \mathrm{a} / \mathrm{c} / \mathrm{d} / \mathrm{e}(8.6 \%)$. No samples belonging to subtype $3 b$ were detected.

The relative prevalence of each subtype within the different groups studied showed interesting features since significant or highly significant differences were observed among transfused patients and IVDU, respectively, comparing the specific subtypes with their prevalence within the whole population (two unpaired proportions, two-sided test). Although two other groups of patients showed statistically significant differences as well, the scarce number of patients included within each of

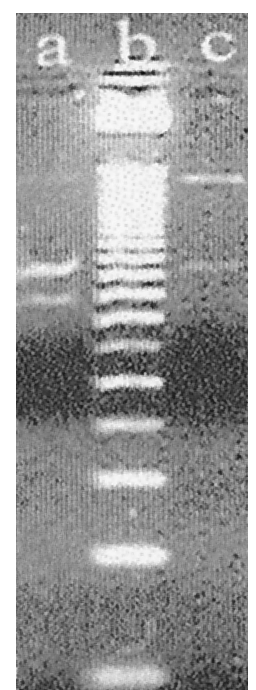

FIG. 1. 5'UTR-core RFLP. Amplicons (647 bp) were digested with AccI and run on a $4 \%$ agarose gel which was stained with ethidium bromide. Lane a, mixed $\mathrm{HCV}$ infection involving subtypes $1 \mathrm{a}$ (predominant) and 1b; lane b, 25-bp ladder; lane $\mathrm{c}$, subtype $1 \mathrm{~b}$ restriction pattern. 


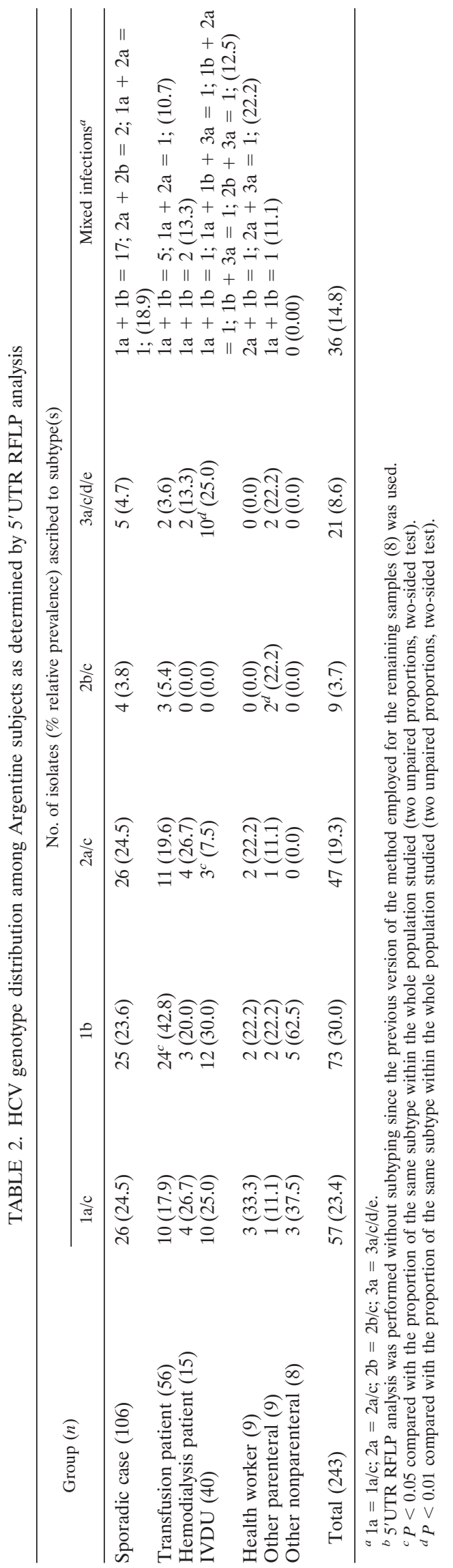

them precludes any further conclusions (Table 2). Among transfusion patients a higher prevalence of $1 \mathrm{~b}$ subtype $(P<$ 0.05 ) was observed. In contrast, among IVDU, the contribution of subtype $3 \mathrm{a} / \mathrm{c} / \mathrm{d} / \mathrm{e}$ was significantly higher compared to its own incidence within the (non-IVDU) whole population $(P<$ 0.01 ), while there was less subtype $2 \mathrm{a} / \mathrm{c}$ compared to the overall rates $(P<0.05)$. Interestingly, when $\mathrm{HCV}$ genotype $3 \mathrm{a} / \mathrm{c} / \mathrm{d} / \mathrm{e}$ was plotted against age, a striking contribution was ascribed to young ([21- to 40-year old] mainly IVDU) patients (Fig. 2). A statistically significant association was observed between subtype 3a with both the above-mentioned age range group and IVDU (chi-square test: $P=0.0026$ versus the remaining subjects $[n=222]$ and $P=0.0088$ versus other parentally infected patients $[n=83])$. Likewise, subtype 1a was significantly more prevalent among the 21- to 40-year-old group compared with the remaining age ranges (chi-square test: $P=0.0001$ versus those $<20$ years old; $P=0.0317$ versus those 41 to 60 years old; and $P=0.001$ versus those $>60$ years old).

Out of the $243 \mathrm{HCV}$ infected sera, 36 mixed infections $(14.8 \%)$ were detected which were predominantly $1 \mathrm{a} / \mathrm{c}$ and $1 \mathrm{~b}$ ( $n=26 ; 72.2 \%$ of mixed infections). The majority of these $1 \mathrm{a} / \mathrm{c}$ and $1 \mathrm{~b}$ mixed infections were mainly detected among sporadic cases, which was a significant contribution compared to the whole incidence of these subtypes among other groups $(P<$ $0.01)$. Randomly selected mixed infections were entirely confirmed either by HCV serologic genotyping (for mixed types, see below) or by documentation of a unique $A c c$ I restriction site only present among 1a isolates at the core region (Fig. 1) $(2,3)$.

Primer-specific amplification of the core (core PCR). PCR amplification using subtype-specific primers within the core genomic region was performed as described by Okamoto et al. $(30,31)$ on 56 samples (Table 1). We observed no amplification products from 26 isolates (46.4\%). Six samples exhibited discordant typing results compared to 5'UTR RFLP analysis. The subtype assignment in the remaining 24 samples was consistent with the data obtained by RFLP. Subsequent use of an improved version of this methodology (26) allowed us to detect initially nontypeable $2 \mathrm{c}$ isolates (i.e., serum 874 ).

Sequence analysis. Fifty samples were selected for 5'UTR sequence comparison by phylogenetic analysis of clades and types and are identified in Fig. 3. These studies demonstrated that 35 isolates belonged to clade 1 (70\%), 10 belonged to clade $2(20 \%)$, and 5 belonged to clade $3(10 \%)$. However, when results from these 50 sequenced isolates were compared with the experimental results from 5'UTR RFLP analysis it was shown (by the latter methodology) that four samples contained mixed infections (i.e., 1a plus $1 \mathrm{~b}, n=3$; 1 a plus $1 \mathrm{~b}$ plus 3a, $n=1$ ) composed of predominant genomes (detected by both cDNA sequencing and RFLP analysis), in addition to minor HCV populations detected only by RFLP analysis (Table 1).

With regard to the NS5B isolates studied, only 15 out of 35 (42.9\%) could be detected by RT-nested PCR amplification (Table 1), reflecting the known different sensitivity to detect HCV RNA based upon RT-PCR amplification on this region with regard to the most conserved $5^{\prime} \mathrm{UTR}(5,49)$. NS5B sequencing and the corresponding phylogenetic analysis showed that five samples belonged to subtype la, five samples belonged to subtype $1 \mathrm{~b}$ and the remaining five samples belonged to $2 \mathrm{c}$ (Fig. 4). Ten out of 15 samples (66.6\%) showed results concordant with 5'UTR RFLP analysis (see below).

Both phylogenetic trees were supported by bootstrap values higher than $70 \%$ for clade and HCV subtype assignment, respectively.

The chance of PCR contamination, and therefore potential 


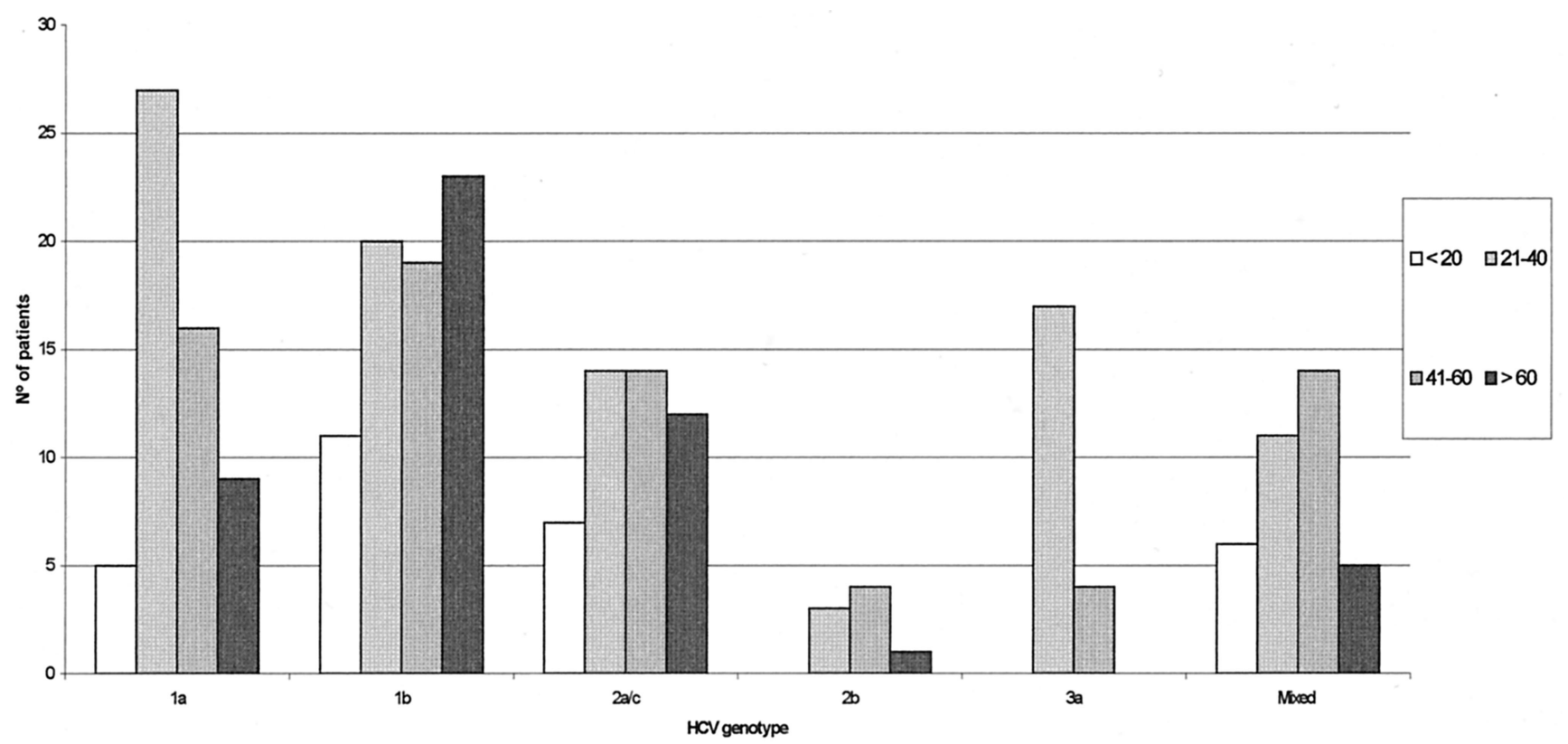

FIG. 2. HCV genotype distribution according to age range (years).

mistyping, within samples inter se from both 5'UTR and NS5B regions was exhaustively investigated and ruled out since different controls confirmed the accuracy of data, with (i) RNA from two different aliquots, (ii) cDNA bidirectionally sequenced, and (iii) absence of $100 \%$ homology with any other product from the same regions.

HCV serologic genotyping. Three selected samples were confirmed as showing mixed infections ascribed to different genotypes (i.e., 1 plus $2, n=1 ; 1$ plus $3, n=2$ ).

Discrepant HCV typing results. Table 3 summarizes the discrepancies we observed using the three different approaches for subtype assignment where NS5B amplicons could be obtained. Subtype assignment based upon 5'UTR RFLP and NS5B sequence analysis was concordant in 10 of the 15 samples. One of these discrepant samples was the initial serum from a health care worker (sample 760) which appeared to have a mixed population detected in the 5'UTR, the minor one of which was selectively amplified within the NS5B region (subtype 1a). Later during infection (sample 874), the major population (subtype $2 \mathrm{a} / \mathrm{c}$ ) was the only one detected in both 5'UTR RFLP analysis and within the NS5B sequence analysis. The four remaining discrepant samples were subtype la and $2 \mathrm{c}$ based upon NS5B sequence analysis, but subtypes la/c, lb, $3 \mathrm{a} / \mathrm{c} / \mathrm{d} / \mathrm{e}$, and $2 \mathrm{a} / \mathrm{c}$ based upon $5^{\prime}$ UTR RFLP analysis. Six other samples failed to show concordant results between $5^{\prime} \mathrm{UTR}$ RFLP analysis and core PCR (i.e., $2 \mathrm{a} / \mathrm{c}$ versus $1 \mathrm{a} ; 2 \mathrm{a} / \mathrm{c}$ versus $3 \mathrm{a}$; la versus $3 \mathrm{a}(n=2)$; $1 \mathrm{~b}$ and $3 \mathrm{a}$ versus $1 \mathrm{a}, 1 \mathrm{~b}$, and $3 \mathrm{a}$; and $3 a$ versus $1 b$ and $2 b$, respectively), but NS5B PCR amplification consistently rendered negative results.

5'UTR-core RFLP. Mixed infections involving 1a plus $1 \mathrm{~b}$ detected by 5'UTR RFLP were confirmed by AccI digestion (2, 3) of amplicons from 10 randomly selected samples (Fig. 1).

Biochemical evaluation of liver function. To determine the clinical significance of infection with different HCV genotypes, we analyzed the relationship of serum ALT levels from 97 samples, approximately representing the same genotype distribution observed in the whole population studied. Data are shown in Table 4. No statistical difference was observed when ALT levels from serum samples exhibiting different HCV types or subtypes were compared. However, ALT values from patients infected with more than one type or subtype were significantly higher than those observed in patients infected with genotype $1(P=0.0108)$ or $3(P=0.02)$ but not with genotype 2; remarkably, when a specific subtype was considered, lb, ALT values differed with high statistical significance compared to values for mixed infections $(P=0.0032)$.

\section{DISCUSSION}

These studies provide the most comprehensive data to date on HCV subtypes present in chronically infected patients referred to medical treatment in Argentina between 1993 and 1999.

Out of 547 viremic patients, 243 sera were included within these investigations, and the HCV genotype was determined by RFLP analysis of the 5'UTR region (9) while selected subsets were also evaluated by primer-specific core region amplification $(30,31)$ and amplification and sequencing of a fragment derived from the NS5B genome region $(6,11)$.

At least four major points deserve to be highlighted: (i) the overall HCV subtype distribution; (ii) the relatively high prevalence of mixed infections; (iii) the inferred high prevalence of subtype $2 \mathrm{c}$ within $2 \mathrm{a} / \mathrm{c}$ isolates; and (iv) the observation of discrepant results when different $\mathrm{HCV}$ genomic regions were analyzed.

Firstly, only genotypes 1,2 , and 3 were detected with decreasing prevalence, as shown in Table 2. Genetic analysis using $5^{\prime}$ UTR RFLP indicates that $23.5 \%$ of infections are subtype $1 \mathrm{a} / \mathrm{c}, 30.0 \%$ are subtype $1 \mathrm{~b}, 23.0 \%$ are subtype $2 \mathrm{a} / \mathrm{c}$ or $2 \mathrm{~b} / \mathrm{c}, 8.6 \%$ are subtype $3 \mathrm{a} / \mathrm{c} / \mathrm{d} / \mathrm{e}$, and $14.8 \%$ are mixed infections. These results confirm and strengthen our initial data (33, 41). Thus, HCV genotype distribution in Argentina closely resembles the reported data from other Western countries. However, it is worth mentioning that other Argentine researchers have recently observed the circulation of a small percentage of strains ascribed to either genotype 4 or 5 among hemophiliacs (36). The higher prevalence of clade 3 observed among IVDU with regard to other groups studied $(P<0.01)$ 


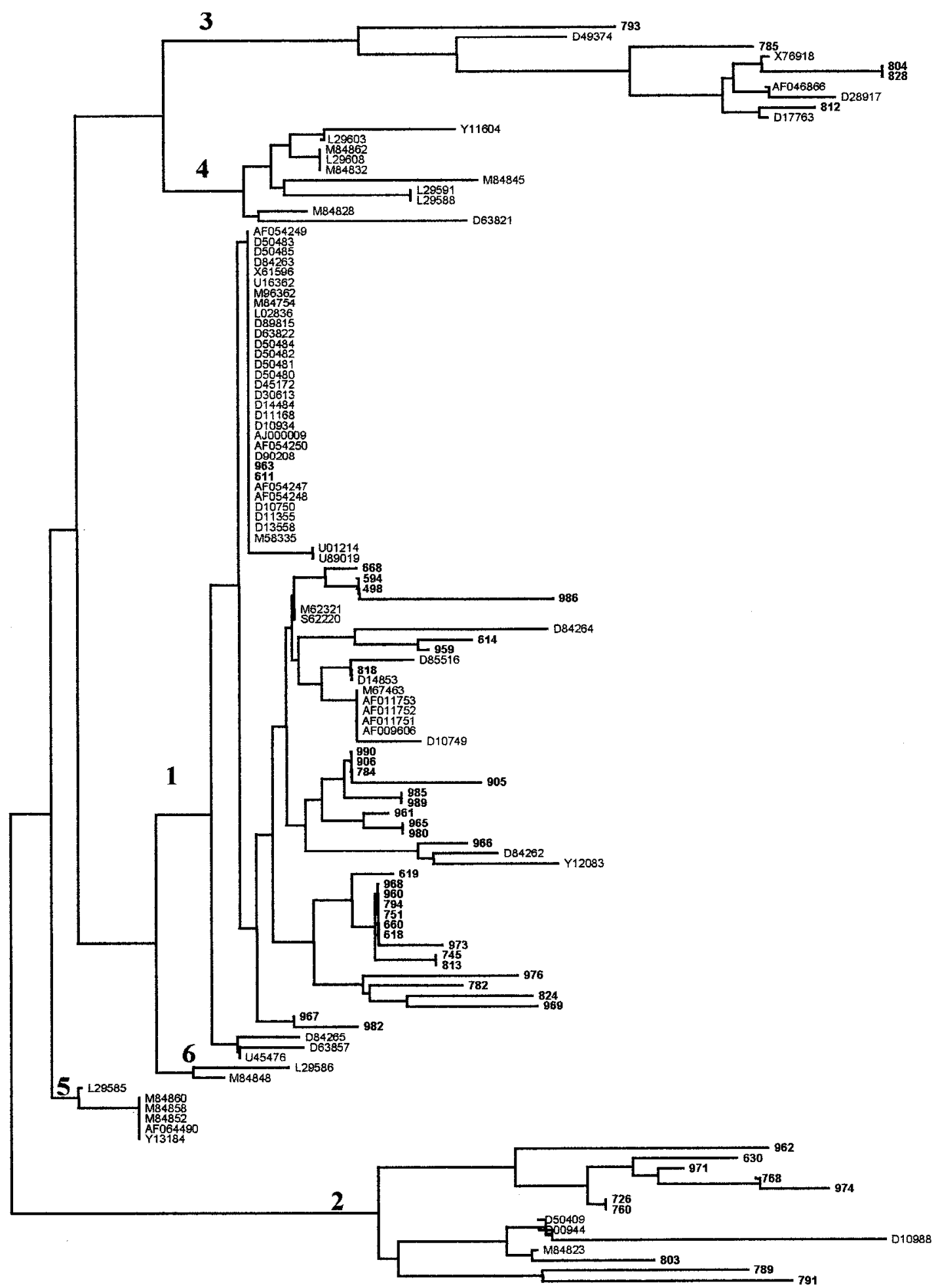

FIG. 3. The phylogenetic tree shown is based on 124 sequences derived from the $5^{\prime} \mathrm{UTR}$ of HCV. Argentine HCV sequences $(n=50)$ are indicated by their isolate numbers (in boldface type): samples 498, 594, 611, 614, 618, 619, 630, 660, 668, 726, 745, 751, 760, 768, 782, 784, 785, 789, 791, 793, 794, 803, 804, 812, 813, 818, 824, $828,905,906,959,963,965,969,971,973,974,976,980,982,985,986,989$, and 990 correspond to accession numbers from GenBank AF041264 to AF041313, respectively. Sequences used as references for the phylogenetic tree $(n=74)$ are identified by their accession number from GenBank. Note that major HCV clades from 1 to 6 are indicated. The DNA alignments were generated with the Clustal X program. The phylogenetic tree was constructed with the TREEVIEW program. Bootstrap analysis was performed by using the programs SEQBOOT (to generate 1,000 reshuffled sequences), CONSENSE, and RETREE at the midpoint of the longest branch for comparative purposes (PHYLIP package, version 3.5c). Bar, number of nucleotide substitutions per site. 


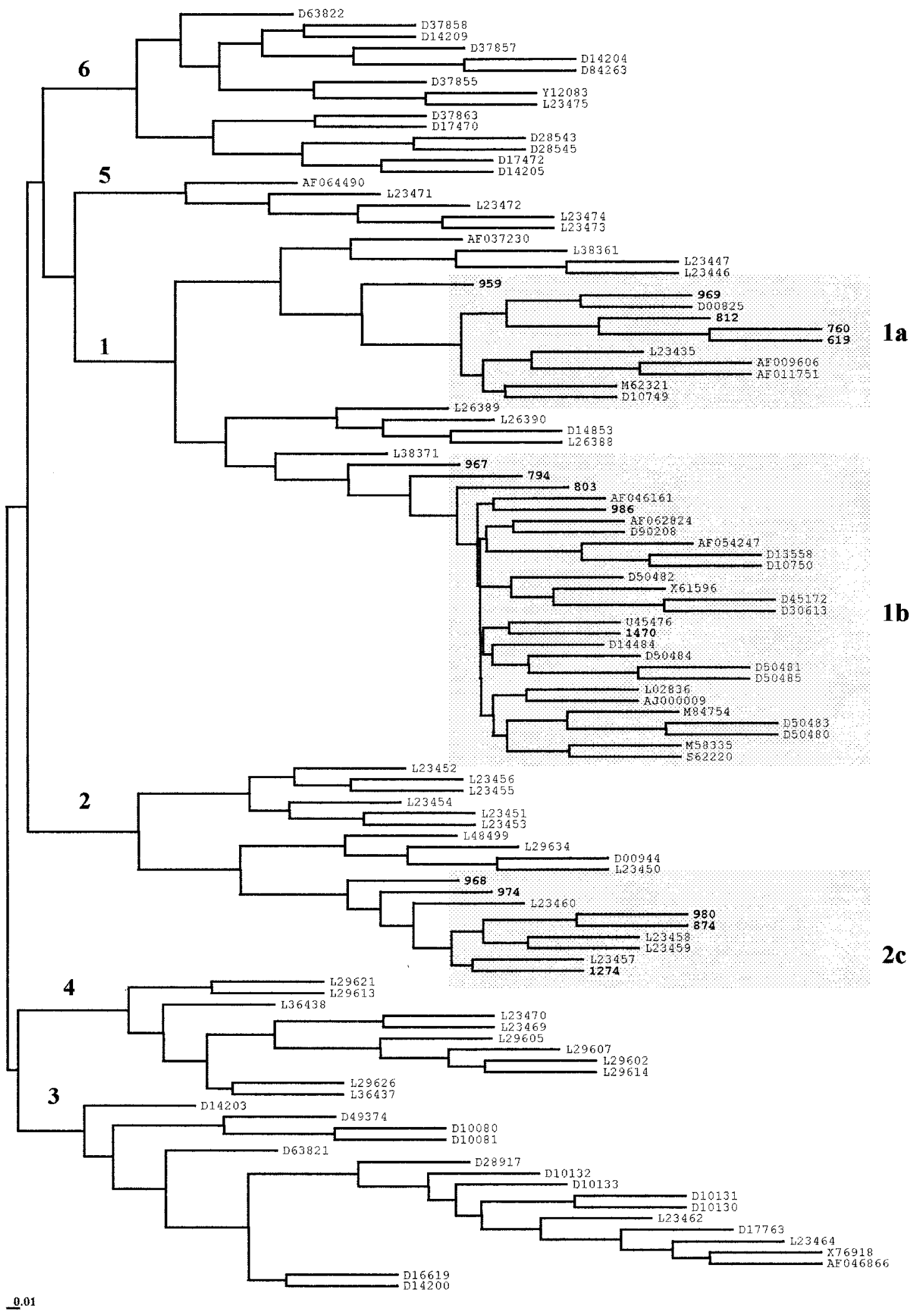

FIG. 4. The phylogenetic tree shown is based on sequences derived from the NS5B region of HCV. Argentine HCV sequences $(n=15)$ are indicated by their isolate number (in boldface type): samples $619,760,794,803,812,874,959,967,968,969,974,980,986,1274$, and 1470 correspond to accession numbers from GenBank AF041314 to AF041328, respectively. Sequences used as references for the phylogenetic tree $(n=99)$ are identified by their accession number from GenBank. Note that major HCV clades from 1 to 6 are indicated. Shaded boxes indicate bootstrap values. Bar, number of nucleotide substitutions per site. 
TABLE 3. Discrepancies among different methodologies for HCV genotyping of Argentine isolates

\begin{tabular}{lccc}
\hline \multirow{2}{*}{$\begin{array}{c}\text { Isolate no. } \\
\text { (population }^{a} \text { ) }\end{array}$} & \multicolumn{3}{c}{ Type(s) according to: } \\
\cline { 2 - 4 } & Core PCR & 5'UTR RFLP analysis $^{\prime}$ & NS5B sequencing \\
\hline $619(\mathrm{SC})$ & $\mathrm{NT}^{b}$ & $1 \mathrm{a}$ & $1 \mathrm{a}$ \\
$760(\mathrm{HW})^{c}$ & $1 \mathrm{~b}$ & $2 \mathrm{a} / \mathrm{c}+1^{d}$ & $1 \mathrm{a}$ \\
$794(\mathrm{SC})$ & $\mathrm{NT}$ & $1 \mathrm{~b}$ & $1 \mathrm{~b}$ \\
$803(\mathrm{~T})$ & $\mathrm{NT}$ & $2 \mathrm{a} / \mathrm{c}$ & $1 \mathrm{a}$ \\
$812(\mathrm{IVDU})$ & $\mathrm{NT}$ & $3 \mathrm{a}$ & $1 \mathrm{a}$ \\
$874(\mathrm{HW})^{c}$ & $\mathrm{NT}$ & $2 \mathrm{a} / \mathrm{c}$ & $2 \mathrm{c}$ \\
$959(\mathrm{NONPR})$ & $\mathrm{NT}$ & $1 \mathrm{a}$ & $1 \mathrm{a}$ \\
$967(\mathrm{IVDU})$ & $\mathrm{NT}$ & $1 \mathrm{~b}$ & $1 \mathrm{~b}$ \\
$968(\mathrm{~T})$ & $\mathrm{NT}$ & $1 \mathrm{~b}$ & $2 \mathrm{c}$ \\
$969(\mathrm{HW})$ & $\mathrm{NT}$ & $1 \mathrm{a}$ & $1 \mathrm{a}$ \\
$974(\mathrm{SC})$ & $\mathrm{NT}$ & $2 \mathrm{a} / \mathrm{c}$ & $2 \mathrm{c}$ \\
$980(\mathrm{NOPR})$ & $\mathrm{NT}$ & $1 \mathrm{a}$ & $2 \mathrm{c}$ \\
$986(\mathrm{SC})$ & $\mathrm{NT}$ & $1 \mathrm{~b}$ & $2 \mathrm{~b}$ \\
$1274(\mathrm{SC})$ & $\mathrm{NT}$ & $2 \mathrm{a} / \mathrm{c}$ & $1 \mathrm{~b}$ \\
$1470(\mathrm{~T})$ & $\mathrm{NT}$ & $1 \mathrm{~b}$ &
\end{tabular}

${ }^{a}$ SC, sporadic cases; HW, health workers; T, transfusion patients; NONPR, nonspecified other nonparenteral risks; NOPR, nonspecified other parenteral risks.

${ }^{b}$ NT, not typeable.

${ }^{c}$ Nucleotide sequences obtained from two different samples from the same patient after 6 months of elapsed time.

${ }^{d}$ Minor population: type 1 (plus $2 \mathrm{a} / \mathrm{c}$ ) was also detected in 3 out of 10 RT-nested 5'UTR PCR amplifications followed by RFLP analysis.

${ }^{e}$ When $2 \mathrm{c}$-specific primers were used, this sample became characterized. Another group of six sera showed discrepant results between core PCR and 5'UTR RFLP, but NS5B amplification rendered negative results.

is in agreement with previous reports from Europe (35). Together with a recent report from Argentina (14), these are the first studies from another part of the world which also suggest that IVDU may carry selective subtypes.

Secondly, the presence of HCV mixed infections is an interesting field of current research. Two previous reports from the authors showed dissimilar results at this specific point. We had initially detected a high proportion of mixed infections, reaching up to $45.4 \%$ (33), while in a later study we did not detect mixed infections (41). These discrepancies might be explained by considering the typing methodologies that we employed each time. In the former, a core-based specific PCR method was applied $(30,31)$, and it is known that this procedure may readily detect different genotypes but produces a certain degree of mispriming (23). In the later study, a majority of typing results was obtained by predicted RFLP patterns from 5'UTR nucleotide sequencing. It seems plausible that only predominant genomes would have been detected, since purified PCR products were then directly sequenced. Therefore, the existence of minor HCV populations could not be ruled out. Besides, distinct populations studied exhibited differential risk of multiple exposure to HCV sources (e. g., hemophiliacs, not included in our second survey [41]).

In the present study, we have analyzed all samples by using RFLP, which is reportedly known to need roughly equimolar concentrations for detecting mixed infections implying at least two different HCV subtypes (9). Among $243 \mathrm{HCV}$-infected patients, 36 exhibited mixed infections (14.8\%). This percentage is higher than the observed value for samples from other geographic areas in previous epidemiological studies using the same methodology (46) although it is approximately similar to the rate reported in Venezuela (38). The possibility of RTnested PCR contaminations was entirely ruled out since RNA was extracted from two separate serum aliquots and subsequently amplified. All RFLP results regarding the predomi- nant viral population were in agreement with data obtained by cDNA sequencing of the same $5^{\prime} \mathrm{UTR}(n=50)$. Subtypes $1 \mathrm{a} / \mathrm{c}$ and $1 \mathrm{~b}$ accounted for most of the mixed infections (72.2\%), although 5'UTR RFLP methodology might have mistyped a very low number of the samples due to the unusual presence of A or $G$ at position -99 within subtypes 1 b or $1 \mathrm{a}(9)$. This contribution was also observed among sporadic cases, reflecting the high prevalence of these subtypes in the general population of Buenos Aires, Argentina.

Data regarding mixed infections were documented using different approaches, including (i) 5'UTR RFLP analysis as mentioned above; (ii) analysis of a second genomic region looking for a specific $A c c$ I restriction site (cleavage at nucleotide 184 from the putative AUG start codon) at the core region $(n=10)$, which was reported to be indicative of subtype la (Fig. 1, lane a, corresponding to a mixed infection involving 1a plus 1 b) but was absent among $1 \mathrm{~b}$ isolates (Fig. 1, lane c) (2,3); and (iii) detecting the immune response against type-specific NS4 peptides. Concordant results obtained were in agreement with data already reported (27) when comparing 5'UTR RFLP analysis, NS4 serologic genotyping, and 5'UTR sequencing, which also showed $100 \%$ concordance among them.

Several hypotheses might be considered for mixed $\mathrm{HCV}$ infections: (i) simultaneous coinfection with different types and/or subtypes; (ii) superinfection of HCV-infected but nonprotected individuals, as documented in experimentally inoculated primates (29) or naturally infected patients (22); (iii) HCV genotype turnover as observed among dialyzed (37) and hemophilic $(12,39)$ patients; (iv) HCV genotype overtake phenomena (which may last up to 1 to 8 months) (22); and (v) selective replicative advantage of genotype 1 (22). Moreover, it should be taken into account that the daily produced heterogeneous quasispecies belonging to a given genotype could temporarily fluctuate $(10,15)$. The simultaneous coinfection with different genotypes might imply a large cohort of individuals that already have mixed infections and the efficient transmission of all strains. Conversely, if superinfection were the main cause of mixed infections, it should be envisaged to occur more frequently among IVDU. Since this was not the case (only 5 out of 40 patients [12.5\%]) potential explanations should consider both their younger age (Fig. 2) and (short) time of intravenous drug addiction. HCV genotype overtake phenomena and subsequent replacement have been observed in longitudinal studies of hemophiliacs $(12,39)$ where multiple exposures were documented. Likewise, this fact might account for a certain percentage of mixed infections within the population studied. For unknown reasons, type 1 (and, if present, subtype 1b) is frequently predominant in donor-recipient pairs of genotypes when orthotopic liver transplantation patients are mon-

TABLE 4. Serum ALT values according to HCV genotype distribution

\begin{tabular}{|c|c|}
\hline $\begin{array}{c}\text { Genotype } \\
\text { (no. of samples) }\end{array}$ & $\begin{array}{c}\mathrm{ALT} \pm \mathrm{SD} \\
\text { (IU/liter) }\end{array}$ \\
\hline Type 1 (51) .......... & $63 \pm 63$ \\
\hline Subtype $1 \mathrm{a} / \mathrm{c}(24)$. & $79 \pm 86$ \\
\hline Subtype $1 b$ (27) ..... & $48 \pm 27$ \\
\hline Type 2 (17) .............. & $62 \pm 60$ \\
\hline Subtype $2 \mathrm{a} / \mathrm{c}(14)$. & $61 \pm 64$ \\
\hline Subtype $2 b / c(3) \ldots$ & $67 \pm 41$ \\
\hline Type $3(12)^{a} \ldots$ & $62 \pm 54$ \\
\hline Mixed infection (1 & $122 \pm 119^{b}$ \\
\hline
\end{tabular}

${ }^{a}$ All $3 \mathrm{a} / \mathrm{c} / \mathrm{d} / \mathrm{e}$.

${ }^{b} P=0.0032$ versus $1 \mathrm{~b} ; P=0.0108$ versus $1 ; P=0.02$ versus 3 . 
itored, thus suggesting a selective replicative advantage (22). Coincidently, 29 out of 36 mixed infections (80.6\%) involved subtype $1 \mathrm{~b}$, a much higher rate than the overall prevalence of such subtype within the whole population studied $(P<0.01)$. Interestingly, ALT values from patients exhibiting $\mathrm{HCV}$ mixed infections showed higher values than those infected with genotype 1 or 3 ( $P=0.0108$ and 0.02 , respectively). However, a cautious interpretation of these data is needed, considering both the limited number of mixed infections analyzed in this study and the usual fluctuation of ALT levels in serum during the natural course of the infection.

Thirdly, regarding HCV type 2 assignment by NS5B sequence analysis, three out of three $2 \mathrm{a} / \mathrm{c}$ isolates (according to 5'UTR RFLP analysis) were finally ascribed to subtype 2c (samples 874, 974, and 1274), in agreement with results obtained by an improved version of the core-based typing assay (Table 3) (26). It is concluded that this subtype might potentially represent an important contribution to local HCV epidemiology, taking into account that (i) $23.0 \%$ of the population studied exhibited type 2 infections $(n=56)$ and (ii) both subtypes $2 \mathrm{a}$ and $2 \mathrm{~b}$ are indistinguishable from subtype $2 \mathrm{c}$ at the $5^{\prime}$ UTR. A high prevalence of subtype $2 c$ has been found among individuals in Italy $(4,16,25,44,47)$, from which a substantial proportion of the Buenos Aires population is descended, due to immigration within this century.

Fourthly, type assignment by 5'UTR RFLP and NS5B phylogenetic analyses exhibited concordant results in 10 of 15 cases studied $(66.7 \%)$, while five samples were discrepant with regard to the previously observed 5'UTR RFLP pattern (Table 3 ). Discrepant results according to the analyzed HCV genomic region have been previously reported as well $(23,27,34)$. In this regard, at least three potential explanations should be considered: (i) the coexistence of HCV genotypes for which primers used during RT-PCR displayed different sensitivity and/or specificity (Table 3, see sample $760: 1$ b at core $2 \mathrm{a}$ /c plus 1 [minor population] at $5^{\prime} \mathrm{UTR}$, and $1 \mathrm{a}$ at NS5B genomic regions); (ii) in vitro template shuffling during RT-PCR amplification; or (iii) hypothetical possibility of recombination between different $\mathrm{HCV}$ variants showing nucleotide sequences belonging to different genotypes throughout viral genomes, as inferred from early reports $(17,19)$. In this regard, thorough studies could not subsequently demonstrate an eventual phenomenon of recombination between HCV genotypes $(44,46)$, but this hypothesis remains to be further explored.

The above-mentioned five discrepant samples were assayed by the core-based specific PCR technique $(30,31)$, but unfortunately only one of them proved positive; therefore, the remaining four samples were classified as nontypeable by this methodology. Factors such as low viral load (50) and lack of exact complementarity between $2 \mathrm{a}$ primers and $2 \mathrm{c}$ sequences accounted for most nontypeable samples (data not shown). This hypothesis was confirmed when samples 874, 974, and 1274 were assayed with a 2c-specific core primer (26).

Considering some limitations of 5'UTR RFLP analysis for HCV subtyping $(9,46)$, despite recently proposed improvements (3), it is currently agreed that it is mandatory to perform simultaneous sequencing of coding genomic regions, which exhibit a greater degree of nucleotide heterogeneity within a given type $(42,45)$. Nevertheless, RFLP is still a widely used tool for epidemiological studies when massive genomic analysis regarding other hepatitis viruses is undertaken $(24,32,33)$.

By means of different methodologies including phylogenetic analysis, this study depicts a general view of circulating $\mathrm{HCV}$ strains during 1993 to 1999 in Buenos Aires, Argentina, and adds information on HCV molecular epidemiology in South America (14, 20, 33, 36-39, 41). After cross-protection studies are performed with different genotypes in primates-as previously investigated with wild-type strains (29) - potential immunogens for humans are expected to be developed $(1,7,8,18$, 51; M. Houghton, Q.-L. Choo, G. Kuo, D. Chien, A. Weiner, M. Selby, L. Consens, S. Coates, R. Ralston, H. Davis, J. Kansopon, K. Berger, S. Wong, M. Wininger, C. Dong, K. Crawford, M. Chin, E. Glazer, M. Jennings, E. Muchmore, D. Rosa, and S. Abrignani, Abstr. IX Triennial Int. Symp. Viral Hepat. Liver Dis., abstr. 150, 1996). Our data should be taken into account when future $\mathrm{HCV}$ vaccines are constructed based upon geographical and epidemiological criteria.

\section{ACKNOWLEDGMENTS}

This study was supported partly by grants HDP/HDR (DRC/RG/ ARG/92-804) from the Pan-American Health Organization, PIP 6554/97 and PIP 842/98 from CONICET, BID 802/OC-AR- PICT 04977/99 from FONCYT, from the Fundación Florencio Fiorini, and from Universidad del Salvador.

\section{REFERENCES}

1. Abrignani, S., and D. Rosa. 1998. Perspectives for a hepatitis C virus vaccine. Clin. Diagn. Virol. 15:181-185.

2. Andonov, A., and R. K. Chaudhary. 1994. Genotyping of Canadian hepatitis C virus isolates by PCR. J. Clin. Microbiol. 32:2031-2034.

3. Buoro, S., S. Pizzighella, R. Boschetto, L. Pellizzari, M. Cusan, R. Bonaguro, C. Mengoli, C. Caudai, M. Padula, P. E. Valensin, and G. Palù. 1999. Typing of hepatitis $\mathrm{C}$ virus by a new method based on restriction fragment length polymorphism. Intervirology 42:1-8.

4. Cammarota, G., F. Maggi, M. L. Vatteroni, L. Da Prato, L. Barsanti, M. Bendinelli, and M. Pistello. 1995. Partial nucleotide sequencing of six subtype 2c hepatitis C viruses detected in Italy. J. Clin. Microbiol. 33:2781-2784.

5. Castillo, I., J. Bartolome, J. A. Quiroga, and V. Carreño. 1992. Comparison of several PCR procedures for detection of serum HCV-RNA using different regions of the HCV genome. J. Virol. Methods 38:71-79.

6. Chan, S. W., F. McOmish, E. C. Holmes, B. Dow, J. F. Peutherer, E. Follett, P. L. Yap, and P. Simmonds. 1992. Analysis of a new hepatitis C virus type and its phylogenetic relationship to existing variants. J. Gen. Virol. 73:11311141.

7. Choo, Q.-L., G. Kuo, R. Ralston, A. Weiner, D. Chien, G. Van Nest, J. Han, K. Berger, K. Thudium, C. Kuo, J. Kansopon, J. McFarland, A. Tabrizi, K. Ching, B. Moss, L. B. Cummins, M. Houghton, and E. Muchmore. 1994. Vaccination of chimpanzees against infection by the hepatitis $\mathrm{C}$ virus. Proc. Natl. Acad. Sci. USA 91:1294-1298.

8. Cooreman, M. P., and E. M. Schoondermark-Van de Ven. 1996. Hepatitis C virus: biological and clinical consequences of genetic heterogeneity. Scand. J. Gastroenterol. Suppl. 218:106-115.

9. Davidson, F., P. Simmonds, J. C. Ferguson, L. M. Jarvis, B. C. Dow, E. A. C. Follet, A. J. Keller, T. Kruisius, C. Lin, G. A. Medgyesu, H. Kiyokawa, G. Olim, G. Duraisamy, T. Cuypers, A. A. Seed, D. Ten, J. Conradie, M. C. Kew, M. Lin, C. Nuchaprayoon, O. K. Ndimbe, and P. L. Yap. 1995. Survey of major genotypes and subtypes of hepatitis $\mathrm{C}$ virus using RFLP of sequences amplified from the $5^{\prime}$ non-coding region. J. Gen. Virol. 76:1197-1204.

10. Domingo, E., E. Baranowski, C. M. Ruiz-Jarabo, A. M. Martin-Hernández, J. C. Sáiz, and C. Escarmís. 1998. Quasispecies structure and persistence of RNA viruses. Emerg. Infect. Dis. 4:521-527.

11. Enomoto, N., A. Takada, T. Nakao, and T. Date. 1990. There are two major types of hepatitis $C$ virus in Japan. Biochem. Biophys. Res. Commun. 170: 1021-1025.

12. Eyster, M. E, K. E. Sherman, J. J. Goedert, A. Katsoulidou, and A. Hatzakis for the Multicenter Hemophilia Cohort Study. 1999. Prevalence and changes in hepatitis $\mathrm{C}$ virus genotypes among multitransfused persons with hemophilia. J. Infect. Dis. 179:1062-1069.

13. Felsenstein, J. 1993. PHYLIP inference package, version 3.5c. Department of Genetics, University of Washington, Seattle.

14. Findor, J. A., J. A. Sorda, J. Daruich, E. Bruch Igartua, E. Manero, A. Avagnina, D. Benbassat, J. Rey, and M. Nakatsuno. 1999. Distribution of the genotypes of hepatitis $\mathrm{C}$ virus in intravenous drug addicts in Argentina. Medicina (Buenos Aires) 59:49-54.

15. Forns, X., R. H. Purcell, and J. Bukh. 1999. Quasispecies in viral persistence and pathogenesis of hepatitis C virus. Trends Microbiol. 7:402-410.

16. Guadagnino, V., T. Stroffolini, M. Rapicetta, A. Costantino, L. A. Kondili, F. Menniti-Ippolito, B. Caroleo, C. Costa, G. Griffo, L. Loiacono, V. Pisani, A. Foca, and M. Piazza. 1997. Prevalence, risk factors, and genotype distribution of hepatitis $\mathrm{C}$ virus infection in the general population: a communitybased survey in southern Italy. Hepatology 26:1006-1011.

17. Honda, M., S. Kaneko, M. Unoura, K. Kobayashi, and S. Murakami. 1993. Sequence analysis of putative structural regions of hepatitis $\mathrm{C}$ virus isolated 
from 5 Japanese patients with hepatocellular carcinoma. Arch. Virol. 128: $163-169$.

18. Inchauspé, G. 1999. DNA vaccine strategies for hepatitis C. J. Hepatol. 30: 339-346.

19. Kato, N., Y. Ootsuyama, T. Tanaka, M. Nakagawa, T. Nakazawa, K. Muraiso, S. Ohkoshi, M. Hijikata, and K. Shimotohno. 1992. Marked sequence diversity in the putative envelope proteins of hepatitis $\mathrm{C}$ viruses. Virus Res. 22:107-123.

20. Krug, L. P., V. R. Lunge, N. Ikuta, A. S. K. Fonseca, H. Cheinquer, L. S. Ozaki, and S. G. Barros. 1996. Hepatitis C virus genotypes in Southern Brazil. Braz. J. Med. Biol. Res. 29:1229-1232.

21. Kwok, S., and R. Higuchi. 1989. Avoiding false positives with PCR. Nature (London) 339:237-238.

22. Laskus, T., L.-F. Wang, J. Rakela, H. Vargas, A. D. Pinna, A. C. Tsamandas, A. J. Demetris, and J. Fung. 1996. Dynamic behavior of hepatitis C virus in chronically infected patients receiving liver graft from infected donors. Virology 220:171-176.

23. Lau, J. Y. N., M. Mizokami, J. A. Kolberg, G. L. Davis, L. E. Prescott, T. Ohno, R. P. Perrillo, et al. 1995. Application of six hepatitis C virus genotyping systems to sera from chronic hepatitis $\mathrm{C}$ patients in the United States. J. Infect. Dis. 171:281-289.

24. Lindh, M., A.-S. Anderson, and A. Gusdal. 1997. Genotypes, nt 1858 variants, and geographic origin of hepatitis B virus-large-scale analysis using a new genotyping method. J. Infect. Dis. 175:1285-1293.

25. Maggi, F., M. L. Vatteroni, C. Fornai, A. Morraica, M. Giorgi, M. Bendinelli, and M. Pistello. 1997. Subtype 2c of hepatitis C virus is highly prevalent in Italy and is heterogeneous in the NS5a region. J. Clin. Microbiol. 35:161164.

26. Mondelli, M., A. Cerino, F. Bono, A. Cividini, A. Maccabruni, M. Arico, A. Malfitano, G. Barbarini, V. Piazza, L. Minoli, and E. Silini. 1994. Hepatitis $\mathrm{C}$ virus (HCV) core serotypes in chronic HCV infection. J. Clin. Microbiol. 32:2523-2527.

27. Navas, S., I. Castillo, J. Martín, J. A. Quiroga, J. Bartolomé, and V. Carreño. 1997. Concordance of hepatitis C virus typing methods based on restriction fragment length polymorphism analysis in $5^{\prime}$ noncoding region and NS4 serotyping but not in core PCR or a line probe assay. J. Clin. Microbiol. 35: 317-321.

28. Okamoto, H., S. Kobata, H. Tokita, T. Inoue, G. D. Woodfield, P. V. Holland, B. A. Al-Knawy, O. Uzunalimoglu, Y. U. Miyakawa, and M. Mayumi. 1996. A second-generation method of genotyping hepatitis $C$ virus by the polymerase chain reaction with sense and antisense primers deduced from the core gene. J. Virol. Methods 57:31-45.

29. Okamoto, H., S. Mishiro, H. Tokita, F. Tsuda, Y. Miyakawa, and M. Mayumi. 1994. Superinfection of chimpanzees carrying hepatitis C virus genotype II/1b with that of genotype III/2a or I/1a. Hepatology 20:1143111436.

30. Okamoto, H., Y. Sujiyama, S. Okada, K. Kurai, Y. Akahane, Y. Sugai, T. Tanaka, K. Sato, F. Tsuda, Y. Miyakawa, and M. Mayumi. 1992. Typing hepatitis $\mathrm{C}$ virus by polymerase chain reaction with type-specific primers: application to clinical surveys and tracing infection sources. J. Gen. Virol. 73: 673-679.

31. Okamoto, H., H. Tokita, M. Sakamoto, M. Horikita, M. Kojima, H. Iizuka, and S. Mishiro. 1993. Characterization of the genomic sequence of type V (or 3a) hepatitis C virus isolates and PCR primers for specific detection. J. Gen. Virol. 74:2385-2390.

32. Oubiña, J. R., V. Mathet, M. Feld, M. P. Della Latta, D. Ferrario, R. Verdun, O. Libonatti, J. Fernández, G. Carballal, D. O. Sánchez, and J. F. Quarleri. 1999. Genetic diversity of GBV-C/HGV strains among HIV infected-IVDU and blood donors from Buenos Aires, Argentina. Virus Res. 65:121-129.

33. Oubiña, J. R., J. F. Quarleri, M. Rudzinski, C. Parks, I. Badía, and S. M. González Cappa. 1995. Genomic characterization of hepatitis C virus from Argentina. J. Med. Virol. 47:97-104.

34. Panigrahi, A. K., J. Roca, S. K. Acharya, S. Jameel, and S. K. Panda. 1996. Genotype determination of hepatitis $\mathrm{C}$ virus from northern India: identifi- cation of a new subtype. J. Med. Virol. 48:191-198.

35. Pawlotsky, J.-M., L. Tsakiris, F. Roudot-Thoraval, C. Pellet, L. Stuyver, J. Duval, and D. Dhumeaux. 1995. Relationship between hepatitis C virus genotypes and sources of infection in patients with chronic hepatitis C. J. Infect. Dis. 171:1607-1610.

36. Picchio, G. R., M. Nakatsuno, C. Boggiano, R. Sabbe, M. Corti, J. Daruich, R. Perez-Bianco, M. Tezanos-Pinto, R. Kokka, J. Wilber, and D. Mosier. 1997. Hepatitis C (HCV) genotype and viral titer distribution among Argentinean hemophilic patients in the presence or absence of human immunodeficiency virus (HIV) co-infection. J. Med. Virol. 52:219-225.

37. Pujol, F. H., M. Devesa, C. L. Loureiro, F. Capriles, and F. Liprandi. 1998. Turnover of hepatitis $\mathrm{C}$ virus genotypes in hemodialysis patients. Arch. Virol. 143:823-827.

38. Pujol, F. H., C. L. Loureiro, M. Devesa, L. Blitz, K. Parra, S. Beker, and F. Liprandi. 1997. Determination of genotypes of hepatitis C virus in Venezuela by restriction fragment length polymorphism. J. Clin. Microbiol. 35:1870 1872 .

39. Quarleri, J. F., I. Badía, V. Mathet, and J. R. Oubiña. 1999. Epidemiología molecular del virus de la hepatitis $\mathrm{C}(\mathrm{HCV})$ en pacientes hemofílicos de edad pediátrica. Pren. Med. Argent. 86:181-185.

40. Quarleri, J. F., V. L. Mathet, M. Feld, D. Ferrario, M. P. Della Latta, R. Verdun, D. O. Sánchez, and J. R. Oubiña. 1999. GBV-C/HGV groups and subgroups: classification by a restriction fragment length polymorphism method based on the phylogenetic analysis of the $5^{\prime}$ untranslated region. J. Clin. Microbiol. 37:1340-1347.

41. Quarleri, J. F., B. H. Robertson, V. Mathet, S. D. Sinha, I. Badía, B. Frider, A. Ferro, C. Galoppo, S. Sookoián, G. Castaño, and J. R. Oubiña. 1998. Genomic and phylogenetic analysis of hepatitis C virus strains from Argentina. Medicina (Buenos Aires). 58:153-159.

42. Robertson, B., G. Myers, C. Howard, T. Brettin, J. Bukh, B. Gaschen, T. Gojobori, G. Maaertens, M. Mizokami, O. Nainan, S. Netesov, K. Nishioka, P. Simmonds, D. Smith, L. Stuyver, and A. Weiner. 1998. Classification, nomenclature, and database development for hepatitis C virus (HCV) and related viruses: proposals for standardization. Arch. Virol. 143:2493-2503.

43. Sanger, F., S. Nicklen, and A. R. Coulson. 1977. DNA sequencing with chainterminating inhibitors. Proc. Natl. Acad. Sci. USA 74:5463-5467.

44. Silini, E., F. Bono, A. Cerino, V. Piazza, E. Solcia, and H. U. Mondelli. 1993. Virological features of hepatitis C virus infections in hemodialysis patients. J. Clin. Microbiol. 31:2913-2917.

45. Simmonds, P., D. B. Smith, F. McOmish, P. L. Yap, J. Kolberg, M. S. Urdea, and E. C. Holmes. 1994. Identification of genotypes of hepatitis C virus by sequence comparisons in the core, E1 and NS-5 regions. J. Gen. Virol. 75: 1053-1061.

46. Smith, B. D., J. Mellor, L. M. Jarvis, F. Davidson, J. Kolberg, M. Urdea, P.-L. Yap, P. Simmonds, and International HCV Collaborative Study Group. 1995. Variation of the hepatitis C virus 5' noncoding region: implications for secondary structure virus detection and typing. J. Gen. Virol. 76: 1749-1761.

47. Spada, E., A. R. Ciccaglione, S. Dettori, P. Chionne, L. A. Kondili, P. Amoroso, V. Guadagnino, M. Greco, and M. Rapicetta. 1998. Genotyping $\mathrm{HCV}$ isolates from Italy by type-specific PCR assay in the core region. Res. Virol. 149:209-218.

48. Thompson, J. D., T. J. Gibson, F. Plewniak, F. Jeanmougin, and D. G. Higgins. 1997. The CLUSTAL X windows interface: flexible strategies for multiple sequence alignment aided by quality analysis tools. Nucleic Acids Res. 25:4876-4882.

49. Xu, L. Z., M. Martinot-Peignoux, P. Marcellin, J. P. Benhamou, and D. Larzul. 1994. Comparison of the sensitivity of nested PCR in the $5^{\prime}$ noncoding and the NS5 regions of the HCV genome. J. Hepatol. 20:598-602.

50. Yuki, N., N. Hayashi, A. Kasahara, H. Hagiwara, K. Ohkawa, H. Fusamoto, and T. Kamada. 1994. Hepatitis $\mathrm{C}$ virus replication and antibody responses toward specific hepatitis C virus proteins. Hepatology 19:1360-1365.

51. Zuckerman, A. J., and J. N. Zuckerman. 1995. Prospects for hepatitis C vaccine. J. Hepatol. 22:97-100. 